\title{
Detection of Microcracking in Concrete Subjected to Elevated Temperature at Very Early Age by Acoustic Emission
}

\author{
Ha Ngoc Son ${ }^{1}$ and Akira Hosoda ${ }^{2}$
}

Received 29 November 2009, accepted 6 April 2010

\begin{abstract}
Microcracks developed considerably in concrete subjected to elevated temperature up to around $60^{\circ} \mathrm{C}$ at early ages, especially in low water-to-binder ratio (0.3) concrete. Microcracking was attributed to the stresses induced by the incompatibility in deformation between mortar and aggregate. Differences of coefficients of thermal expansion (CTE) between mortar and coarse aggregate, autogenous shrinkage of mortar and size of coarse aggregate were important factors influencing deterioration. The tensile strength of concrete was severely affected by the extent of microcracks. Concrete using ground granulated blast furnace slag (GGBFS) suffered worse damage than concrete prepared from ordinary Portland cement alone. Attempts were made to apply the acoustic emission (AE) technique to study the process and mechanism of microcracking. The skills required to practice the AE technique at early ages and at high temperature were carefully considered. AE hits agreed with the test results for deformation and tensile strength. Most of the microcracks occurred within the descending period of temperature and were classified into tensile mode. The use of coarse aggregate with larger CTE, saturated fine lightweight aggregate, and the reduction of the maximum size of the aggregate were greatly effective in reducing microcracking and improving the tensile strength of concrete made with GGBFS. Direct tensile strength was more adversely affected by microcracking than splitting tensile strength.
\end{abstract}

\section{Introduction}

Thermal cracking in concrete at early ages has been studied extensively in the literature. The driving force is shrinkage and thermal deformation under restraint conditions. However, there is still confusion in separating the roles of the two restraints leading to cracking in concrete. One restraint is the constraint of aggregates against the deformation of cement paste and thus mortar. This restriction is defined as mesoscopic restraint in this paper. The other is the restraint in which the deformation of the whole or a part of concrete composite is restricted by an outside factor (macroscopic restraint). This paper deals with the effect of mesoscopic restraint.

The deterioration under mesoscopic restraint is believed to be microcracks generated under the stress induced by the incompatibility in deformations of the concrete's two components: aggregate and matrix. When concrete undergoes a temperature change at early ages, the matrix is subjected to thermal deformation and shrinkage. The volume change of the matrix is constrained by aggregate, which principally deforms thermally. Generally, the coefficient of thermal expansion (CTE) of the matrix is higher than that of coarse aggre-

\footnotetext{
${ }^{1} \mathrm{PhD}$ student, Graduate School of Environment and Information Sciences, Yokohama National University, Japan.

E-mail:sonhn@viettel.vn

${ }^{2}$ Associate Prof., Graduate School of Environment and Information Sciences, Yokohama National University, Japan.
}

gate (Son and Hosoda 2008). Therefore, in the presence of shrinkage, volume change incompatibility is expected in most concretes. The problem is predictably more severe for low water-to-binder $(\mathrm{w} / \mathrm{b})$ ratio, heat cured and massive concretes due to higher autogenous shrinkage and larger temperature change.

Revealing behaviors of concrete at very early ages faces various difficulties in practice. This period is the most unstable in the life of concrete. During this time, concrete changes from the plastic to the hardened phase, strength increases, hydration heat is released, the volume changes, and so on. Therefore, suitable techniques and experimental methods must be carefully considered and employed. The acoustic emission (AE) technique was selected in conjunction with tests for physical and mechanical properties of mortars and concretes. The acoustic emission technique appears to be superior in tracking micro-fractures with high sensitivity and in a time sequence. The AE technique has been extensively studied in concrete engineering. For example, Mlakar et al. (1984), Ohtsu et al. (2001), and Landis and Baillon (2002) dealt with hardened concrete under loading; Kaufmann (2004) applied AE to investigate concrete subjected to freezing-thawing; and Li et al. (1998) and Ramadan et al. (2007) worked with the corrosion of reinforcing steel of reinforced concrete and prestressed concrete. Recently Lura et al. (2009) studied the AE activity of cement pastes during hydration. However, discussions of the application of the $\mathrm{AE}$ technique to concrete during hydration under elevated temperature are not found in the literature.

In Japan, concretes using ground granulated blast furnace slag (GGBFS) have been suffering from severe 
nonstructural cracking, particularly concretes with a high temperature history such as massive or heat cured concrete structures. A significant part of the current research was dedicated to revealing the behaviors of slag concretes in this respect. Based on the research results, practical improvement solutions that can be applied to concrete with GGBFS are proposed.

\section{Experimental program}

The AE technique was employed to detect and characterize active microcracking in various mortar and concrete specimens during heat curing up to around $60^{\circ} \mathrm{C}$. The investigation started at one and half hours after mixing. Since the effect of microcracks is mainly on tensile strength (Akçaoğlu 2002; Celik 2006), verification was carried out by comparing the tensile strength of concretes with that of the respective mortars. The differences in tensile strengths were attributed to the presence of coarse aggregates. Parameters including type of binder, w/b ratio, type of fine aggregate, and type and size of coarse aggregate were determined based on a theoretical model for mesoscopic restraint.

\subsection{Materials - specimens}

The two types of binders used were ordinary Portland cement (OPC) and GGBFS (Table 1). Natural pit-sand and artificial saturated lightweight aggregate (LWA) with maximum particle size of $4.75 \mathrm{~mm}$ were the two types of fine aggregate. The specific weight of LWA in completely dry condition was $1.72 \mathrm{~g} / \mathrm{cm}^{3}$ and water absorption was $13.4 \%$ in weight. Coarse aggregates of different types and maximum sizes were used. Limestone with sizes ranging from 5 to $9.5 \mathrm{~mm}$ and from 5 to $19 \mathrm{~mm}$ was used. The three particle dimension ranges for andesite (a volcanic rock) were 5 to $9.5 \mathrm{~mm}, 5$ to 19 $\mathrm{mm}$ and 5 to $37.5 \mathrm{~mm}$. Coarse aggregates of smaller maximum size were obtained by removing oversize particles. Fine and coarse aggregates were taken from the same batches throughout the experimental series.

The mixture proportions for mortars and concretes are presented in Table 2. A bowl-type mixer was used for both mortar and concrete. The room for storing materials and preparing specimens was kept at a temperature of around $20^{\circ} \mathrm{C}$. The preparation time for specimens, including the installation of strain gauges, wave-guides and sensors, was around 30 minutes. Immediately following preparation, all specimens were sealed and placed in a temperature controlled chamber. As shown in Fig. 1, heating started at two hours, following the addition of mixing water to the mix. In order to ensure approximately the same temperature inside the specimens for different mixes, slight adjustments of maximum temperatures applied to the chamber were taken

Table 1 Chemical composition and physical properties of binders.

\begin{tabular}{|c|c|c|c|c|c|c|c|c|c|c|c|c|}
\hline \multirow{2}{*}{ Type } & \multicolumn{10}{|c|}{ Chemical composition } & \multirow{2}{*}{$\begin{array}{l}\text { Density } \\
\left(\mathrm{g} / \mathrm{cm}^{3}\right)\end{array}$} & \multirow{2}{*}{$\begin{array}{c}\text { Specific } \\
\text { area } \\
\left(\mathrm{cm}^{2} / \mathrm{g}\right)\end{array}$} \\
\hline & $\mathrm{SiO}_{2}$ & $\mathrm{Al}_{2} \mathrm{O}_{3}$ & $\mathrm{Fe}_{2} \mathrm{O}_{3}$ & $\mathrm{CaO}$ & $\mathrm{MgO}$ & $\mathrm{SO}_{3}$ & $\mathrm{TiO}_{2}$ & $\mathrm{MnO}$ & $\mathrm{Na}_{2} \mathrm{O}$ & $\mathrm{K}_{2} \mathrm{O}$ & & \\
\hline OPC & 21.18 & 5.18 & 2.86 & 64.39 & 1.70 & 2.00 & 0.27 & 0.08 & 0.25 & 0.56 & 3.15 & 3390 \\
\hline GGBFS & 33.29 & 13.68 & 0.29 & 42.73 & 5.10 & 1.9 & 0.55 & 0.33 & 0.20 & 0.31 & 2.89 & 4320 \\
\hline
\end{tabular}

Table 2 Mixture proportions.

\begin{tabular}{|l|c|c|c|c|c|c|c|c|c|}
\hline \multicolumn{1}{|c|}{ Mixture } & $\begin{array}{c}\text { Water } \\
\left(\mathrm{kg} / \mathrm{m}^{3}\right)\end{array}$ & $\begin{array}{c}\mathrm{OPC} \\
\left(\mathrm{kg} / \mathrm{m}^{3}\right)\end{array}$ & $\begin{array}{c}\mathrm{GGBFS} \\
\left(\mathrm{kg} / \mathrm{m}^{3}\right)\end{array}$ & $\begin{array}{c}\text { Pit-sand } \\
\left(\mathrm{kg} / \mathrm{m}^{3}\right)\end{array}$ & $\begin{array}{c}\text { Fine } \\
\text { LWA } \\
\left(\mathrm{kg} / \mathrm{m}^{3}\right)\end{array}$ & $\begin{array}{c}\text { Coarse } \\
\text { aggregate } \\
(\text { limestone }) \\
\left(\mathrm{kg} / \mathrm{m}^{3}\right)\end{array}$ & $\begin{array}{c}\text { Coarse } \\
\text { aggregate } \\
(\text { andesite }) \\
\left(\mathrm{kg} / \mathrm{m}^{3}\right)\end{array}$ & $\begin{array}{c}\text { Super- } \\
\text { plasticizer } \\
\left(\mathrm{kg} / \mathrm{m}^{3}\right)\end{array}$ & $\begin{array}{c}\text { W/b } \\
\text { ratio }\end{array}$ \\
\hline M-O-30 & 256 & 853 & - & 1214 & - & - & - & 3.4 & 0.3 \\
\hline M-S-30 & 256 & 427 & 427 & 1158 & - & - & - & 3.4 & 0.3 \\
\hline M-S-LWA-30 & $\begin{array}{c}256 \\
(84)\end{array}$ & 427 & 427 & 384 & 613 & - & - & 4.3 & 0.3 \\
\hline C-O-L20-30 & 170 & 567 & - & 806 & - & $836^{* *}$ & - & 4.0 & 0.3 \\
\hline C-S-L10-30 & 170 & 283 & 283 & 796 & - & $825^{*}$ & - & 3.7 & 0.3 \\
\hline C-S-L20-30 & 170 & 283 & 283 & 796 & - & $825^{* *}$ & - & 4.0 & 0.3 \\
\hline C-S-L20-LWA-30 & 170 & 283 & 283 & 255 & 407 & $825^{* *}$ & - & 4.3 & 0.3 \\
\hline C-S-A10-30 & $176)$ & 283 & 283 & 796 & - & - & $783^{*}$ & 3.7 & 0.3 \\
\hline C-S-A20-30 & 170 & 283 & 283 & 796 & - & - & $783^{* *}$ & 4.0 & 0.3 \\
\hline C-S-A40-30 & 170 & 283 & 283 & 796 & - & - & $783^{* * *}$ & 4.3 & 0.3 \\
\hline C-O-L20-50 & 170 & 340 & - & 900 & - & $933^{* *}$ & - & 0.0 & 0.5 \\
\hline C-S-L20-50 & 170 & 170 & 170 & 893 & - & $926^{* *}$ & - & 0.0 & 0.5 \\
\hline
\end{tabular}


into account. The differences in temperature were probably caused by different amounts of hydration heat released from different dosages and types of binders, and different masses and thermal capacitances of aggregates. Separate trial tests were carried out for the purpose of adjusting the temperature. Firstly, one specimen (same size as those used in the main test) of each mixture was subjected to the temperature regime of the chamber as shown in Fig. 1. The real temperature in each specimen was recorded. Although the same curing temperature was applied, the real maximum temperature inside of the specimens varied for different mixes. For example, the temperature of specimens C-O-L20-30 and C-S-L20-30 was $62.0^{\circ} \mathrm{C}$ and $60.5^{\circ} \mathrm{C}$ respectively. That for mortars was $68.7^{\circ} \mathrm{C}$ and $64.4^{\circ} \mathrm{C}$ respectively. The strategy for the main tests was then the adjustment of the temperature program of the temperature controlled chamber accordingly to ensure that the maximum temperature in every specimen would be $61 \pm 1^{\circ} \mathrm{C}$.

\subsection{Parameters}

Under mesoscopic restraint, the driving force causing microcracking in mortar is induced by deforming incompatibility between mortar and coarse aggregate. The difference in deforming behaviors is attributed to different thermal dilation and contraction (Tazawa et al., 1987; Minami et al., 1990), and shrinkage. Considering one spherical aggregate grain embedded in mortar with infinite boundary (Fig. 2), and assuming that both aggregate and mortar are linearly elastic and isotropic materials, stresses induced in mortar are as follows:

$$
\begin{aligned}
& \sigma_{r}=P(R / r)^{3} \\
& \sigma_{t}=-P(R / r)^{3}
\end{aligned}
$$

where

$R$ : nominal radius of aggregate,

$r$ : distance from center of aggregate,

$P$ : pressure act on the inner face of matrix, with

$$
\begin{gathered}
P=\frac{\Delta D_{t}+S_{m}}{\frac{1+v_{m}}{E_{m}}+\frac{1-2 v_{a}}{E_{a}}} \\
\Delta D_{t}=\left(\alpha_{m}-\alpha_{a}\right) \Delta T
\end{gathered}
$$

where

$\Delta D_{t:}$ difference in thermal deformation between mortar and aggregate,

$\Delta T$ : change in temperature,

$\alpha_{m}, \alpha_{a}$ : coefficient of thermal expansion of matrix and aggregate,

$S_{m}$ : shrinkage of matrix (autogenous shrinkage),

$v_{m}, v_{a}$ : Poisson's ratio of matrix and aggregate,

$E_{m}, E_{a}$ : Young's modulus of matrix and aggregate.

Otsuka et al. (1995) observed thermal microcracks in concrete made with OPC subjected to steam curing with maximum temperature of $55^{\circ} \mathrm{C}$. The two main types of

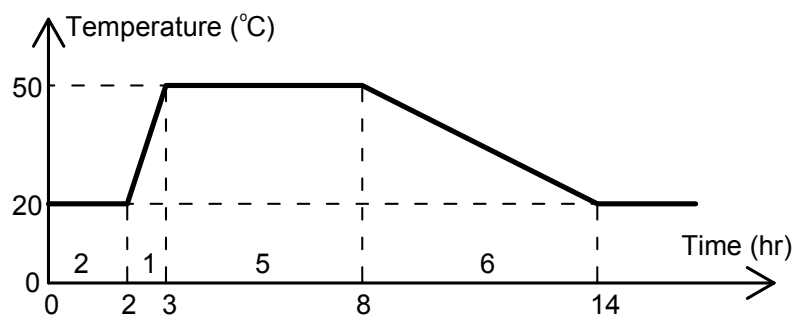

Fig. 1 Curing temperature.

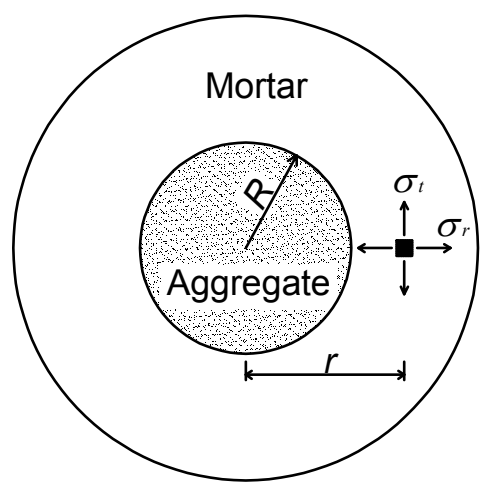

Fig. 2 Model for composite in mesoscopic level.

microcracks found in his study were separation cracks and mortar cracks. Separation cracks formed along the aggregate surface were the result of debonding between the aggregate and the paste. Mortar cracks tended to be at an angle with the interfaces. The separation cracks were probably caused by radial tensile stress $\sigma_{r}$ while mortar cracks were probably due to tangential tensile stress $\sigma_{t}$ or a combination of both stresses.

Our task was to find a solution to restrain microcracking by reducing $\sigma_{r}$ and $\sigma_{t}$. Looking at Eqs. (1) to (4), it was necessary to reduce $P$ and ratio $R / r$. The three ways to decrease $P$ considered here were i) decreasing $\Delta D_{t}$ by constraining temperature change; ii) using aggregate with little difference of CTE compared with that of the mortar and iii) decreasing the autogenous shrinkage of mortar $S_{m}$. Reduction of $R / r$ was achieved by simply reducing the size of aggregate $(R)$. Modification of the temperature rise is apparently a practical approach but was not included in the scope of this paper.

\subsection{Acoustic emission test}

$\mathrm{AE}$ is defined as elastic waves due to microfracturing in a solid (Ohtsu 1995), and is related to an irreversible release of energy. The AE technique allows the detection of elastic waves emitted by microcracking inside the concrete. The recorded AE signal may include components that are not related to material failure and are thus considered as noise, such as friction, impact, electric pulses, and sounds from the environment of the testing place. Rejection of these undesirable components should be carefully considered. 
Figure 3 describes the experimental system for $\mathrm{AE}$ tests. A two-channel AE system was used. The sensors (Fig. 4a) were of the $150 \mathrm{kHz}$ resonant, general-purpose type, with specified operating temperature of $-65^{\circ} \mathrm{C}$ to $177^{\circ} \mathrm{C}$. The AE sensors were coupled with stainless steel wave-guides (Fig. 4b) which were embedded in the specimens. All specimens, wave-guides and AE sensors were placed in a temperature controlled chamber. In each test, two AE sensors were used for two separate specimens cast from the same mix batch, and the averages of the two were taken as the measured values.

Careful consideration was given to the measurement of AE signals in concrete under high temperature condition from a very early age. Noise is a persistent issue of $\mathrm{AE}$ testing. Curing concrete specimens inside a temperature controlled chamber considerably raises the requirement of dealing with significant noise and vibration generated by the dynamic parts of the temperature controlled chamber machinery for AE testing. Trials were conducted to make the practical elimination of noises possible. The solution that was selected was to employ a damping buffer to eliminate vibration and noise from the temperature controlled chamber transmitted by contacting metal parts to the sensors. The electric pulses and the sound waves sent from outside sources through the air were simply taken out from the AE output by setting a threshold level of 40 decibels. Further arguments for the elimination of noise are presented in section 3.4. The sensitivity of the AE sensors used in this research was checked with fully calibrated sensors.

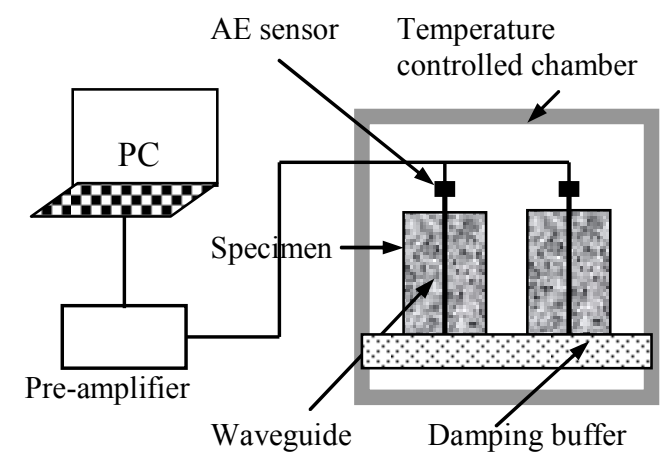

Fig. 3 AE test system.
Since acoustic waves were measured from just one and a half hours after mixing, when the concrete was still in plastic forms, the AE sensors could not be directly coupled to the specimens. To solve this problem, $\mathrm{AE}$ wave-guides were employed (Fig. 4b). Each waveguide consists of a stainless steel rod $4 \mathrm{~mm}$ in diameter, which is embedded in the specimen (Fig. 5a), with a sensor seat at the top of the rod. This small rod can minimize the restraint effect applied to the specimen. A small experiment was conducted to check the function of this wave-guide by comparing $\mathrm{AE}$ responses in the same cylindrical specimens. For one of the specimens, a deformed steel wave-guide bar with diameter of $16 \mathrm{~mm}$ was embedded (the ratio of cross-sectional area of steel over the whole specimen was $2.56 \%$ ). For the other specimen, the aforementioned stainless steel wave-guide was embedded (ratio of steel was $0.16 \%$ ). Some penetrating cracks could be observed in the former after one day of heat curing, probably due to the restraint of the large steel bar, but no cracking was observed in the latter. Correspondingly, the number of AE hits was also much higher with some sudden jumps for the former. For good wave transmission from the wave-guide rod to the sensor seat, the joint between these two parts was made continuous. A stainless steel bar $25 \mathrm{~mm}$ in diameter was lathed until it became as small as $4 \mathrm{~mm}$ in the waveguide rod section while a $2 \mathrm{~mm}$ thick slice at one end of the bar was kept intact to form the sensor seat. The choice of stainless steel as the material was in order to protect the rod from corrosion, which may also generate AE signals. A rubber tight was used to gently attach the sensor to the wave-guide with a thin layer of silicon based grease used in between. As attenuation of AE amplitude in steel is one order of magnitude lower than in concrete (Reginald Hardy 2003), and the same waveguides were used for all tests, the loss of $\mathrm{AE}$ wave amplitude during transmission through the wave-guides was believed to be small and was not considered in the testing results.

Cylindrical steel molds $100 \mathrm{~mm}$ in diameter and 200 $\mathrm{mm}$ in height were used for AE tests (Fig. 5a). To minimize the friction between the concrete specimen and the mold, which is probably a significant source of $\mathrm{AE}$ events that is not the target of this research, a layer of Teflon sheet $0.5 \mathrm{~mm}$ thick was placed covering the whole inside faces of the mold. This Teflon sheet also
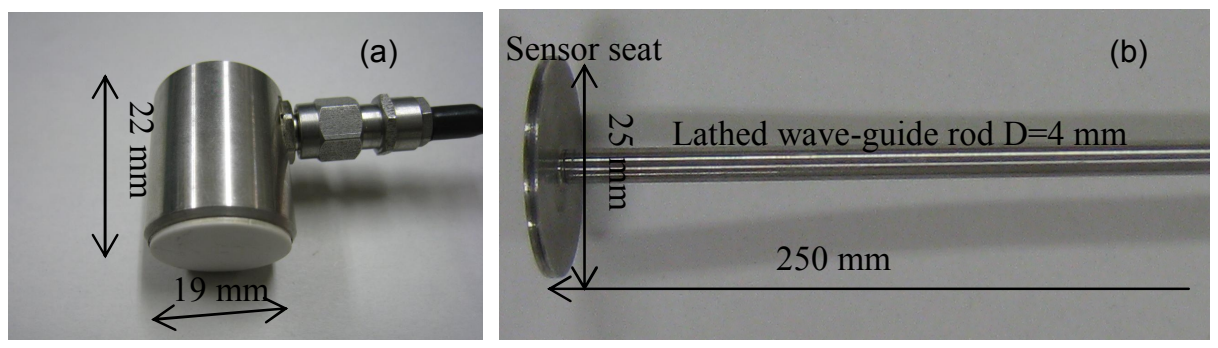

Fig. 4 (a) AE sensor and (b) wave-guide. 
rejected the restraining effect of the mold applied to the specimen.

As for AE tests for mortars, an equivalent volume of mortar in concrete was taken for each specimen. Coarse aggregate was removed while keeping the same proportion of other ingredients of the concrete to retain a mortar mixture. To maintain the same shape and average distance from specimen boundary to the wave-guide, the same cylindrical molds were used for both mortars and concretes whilst only the height of the specimens, 133 $\mathrm{mm}$ for mortar and $200 \mathrm{~mm}$ for concrete, was changed accordingly.

\subsection{Tests of deformation and CTE}

Figure 5b describes the method for measurement of total deformation of the specimen using an embedded strain gauge (Fig. 6). The strain gauge was $60 \mathrm{~mm}$ in length and $4 \mathrm{~mm}$ in diameter. A similar method has been applied elsewhere (Yang et al. 2005). The I shape of the strain gauge improves the mechanical link between the gauge and the concrete. The preparation of specimens was the same as that for the AE test. Recording was started at one and a half hours after the mixing time. Two specimens of the same mix batch were tested at the same time and the average of the two was taken.

Tests of CTE for mortars were conducted at the age of one day. Right before measuring CTE, mortar specimens were subjected to heat curing as shown in Fig. 1. The experimental method was similar to that for the deformation test. Specimens were heated from $20^{\circ} \mathrm{C}$ to $50^{\circ} \mathrm{C}$ in two hours. The temperature was then kept at $50^{\circ} \mathrm{C}$ for two hours before being cooled down to the original level. The CTE was calculated separately for heating and cooling periods, and then the average of these two values was derived. This method allows separation of autogenous shrinkage from the CTE measuring results. Denoting deformation due to both temperature change and autogenous shrinkage, i.e. the deformation measured by strain gauge, of the mortar within heating

(a)

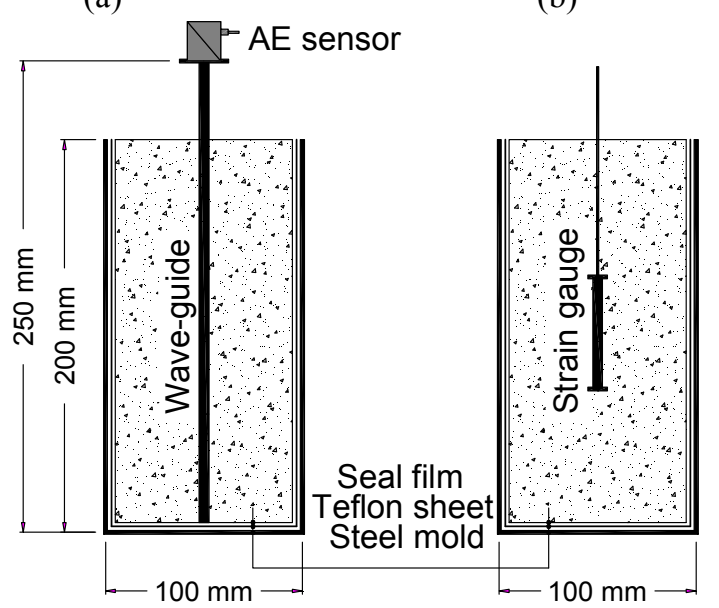

Fig. 5 Specimen preparation for: (a) AE test and (b) deformation test.

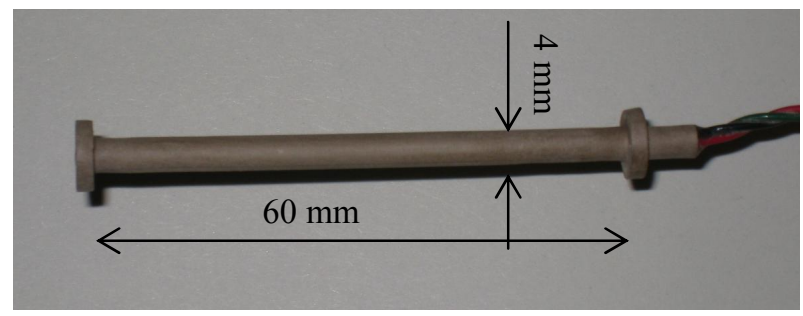

Fig. 6 Strain gauge for measuring deformation of mortar and concrete.

and cooling stages, as $\Delta D_{t, \text { heat }}$ and $\Delta D_{t, \text { cool }}$, respectively; autogenous shrinkages developed in these two periods as $S_{\text {heat }}$ and $S_{\text {cool }}$, respectively; and the absolute change in temperature as $\Delta T$, CTE $\alpha_{\text {mortar }}$ of the mortar is:

$$
\alpha_{\text {mortar }}=\frac{1}{2}\left(\frac{\Delta D_{t, \text { heat }}+S_{\text {heat }}}{\Delta T}+\frac{\Delta D_{t, \text { cool }}-S_{\text {cool }}}{\Delta T}\right)
$$

Autogenous shrinkage of mortar developed during the CTE measuring period was believed to be minor because the measurement was carried out in a rather short time during the deceleration period of cement hydration after the first day of heat curing. Furthermore, the temperature variations were symmetric to each other with respect to the peak point, hence it is possible to suppose that $S_{\text {heat }} \approx S_{\text {cool }}$. Therefore, Eq. (5) will become Eq. (6). It is noted that the specimens were sealed and thus drying shrinkage is not considered here.

$$
\alpha_{\text {mortar }}=\frac{\Delta D_{t, \text { heat }}+\Delta D_{t, \text { cool }}}{2 \Delta T}
$$

For coarse aggregates, cylindrical cores $10 \mathrm{~cm}$ in length and $5 \mathrm{~cm}$ in diameter were taken from the original mass rocks in three perpendicular directions of the rock blocks to measure CTE. The strain gauges used for rock were of the flat type, $30 \mathrm{~mm}$ long, and made by the same manufacturer as the strain gauges used for testing the mortars. Four strain gauges were attached longitudinally on the surface of each core, one at every quarter of the perimeter. The temperature regime was the same as that applied for mortars. Rock cores were also sealed to avoid water loss. In each test, 3 cores were tested. The mean of CTE of the three was then taken.

\subsection{Test of tensile strength}

Splitting and direct tensile strengths of mortars and concretes were investigated at the age of one day following heat curing (Fig. 1). The test procedure for splitting tensile strength complied with JIS A1113:2006. As no standard for direct tensile strength testing currently exists, specimen preparation and loading rate were decided based on the above standard. Specimens for both tests were cylinders $100 \mathrm{~mm}$ in diameter and $100 \mathrm{~mm}$ in height. In the direct tensile strength test, a high-strength bonding agent was used to bind a specimen to two steel end plates to which tensile load was then applied. Three 
specimens were tested in each experiment.

While the direct tensile test applied to specimens cured at normal temperature must deal with only the problem of bleeding, in the case of heat curing, local water loss is an additional problem that weakens the upper part of the specimen. The evaporated water does not leak to the environment but accumulates in the air voids between the specimen and the seal. Under uniaxial tensile force, apparently failure will occur within this weak zone so the test results may not accurately represent the strength of the material. In this research, keeping the upper part of the specimen moist, e.g. by using a saturated membrane, appeared to be effective. For all specimens, the fracture locations in direct tension were randomly distributed around the mid-height but not just around 1 to $3 \mathrm{~cm}$ from the top as in the untreated cases.

Although splitting tensile strength is adopted in most design standards, direct tensile strength is more suitable for research as its nature is closer to the real working status of structures. In this research, only direct tensile strength was used in the discussion of the degree of deterioration of concrete, while splitting tensile strength was also included to study the effect of the degree of microcracking on each type of strength.

\section{Results and discussion}

Investigation for AE, autogenous and thermal deformation, and tensile strength were conducted on mortar and concrete specimens subjected to heat curing at a very early age. Based on the experimental results, internal deteriorations in terms of microcracking in different concretes were clarified. The effects of thermal and autogenous deformation, and aggregate size were analyzed separately. The characteristics of microcracking were also studied.

Since specimens were heated up at a very early age, large initial expansion was observed (Fig. 7). This was mainly due to the high thermal expansion of free water when concrete has not gained a certain strength to resist against dilation. Investigation by Ahmed et al. (2000) showed the CTE of fresh mortar to be around $90 \times 10^{-6} /{ }^{\circ} \mathrm{C}$. Subsequently, in the temperature decline period, the contraction was significantly smaller as compared with the initial expansion. This is likely due to the smaller amount of free water, as water was consumed by hydrating reactions, and the fact that the concrete had built up a rigid skeleton. While the initial thermal expansions strongly depended on the workability of fresh concrete, the shrinkages demonstrated a consistent value. This was revealed when two experiments with the same mix proportion but with different superplasticizer (SP) dosages were carried out (Fig. 7). The mentioned shrinkage in the temperature decline zone, including thermal contraction and autogenous shrinkage, was defined as net shrinkage (Cusson 2008). In the rest of this paper, this net shrinkage of mortar, but not total deformation, will be argued as one of the decisive factors causing deterio- ration in concrete.

\subsection{Effects of thermal and autogenous deforma- tion}

The measured CTE of aggregates and mortars are shown in Fig. 8. It is clear that mortar of GGBFS had very high CTE $\left(14.8 \times 10^{-6} /{ }^{\circ} \mathrm{C}\right)$ as compared with limestone aggregate $\left(6.1 \times 10^{-6} /{ }^{\circ} \mathrm{C}\right)$, while CTE values of OPC mortar $\left(12.3 \times 10^{-6} /{ }^{\circ} \mathrm{C}\right)$ and andesite aggregate $\left(12.2 \times 10^{-6} /{ }^{\circ} \mathrm{C}\right)$ were intermediate.

The net shrinkages measured are presented in Fig. 9. GGBFS mortar demonstrated the largest net shrinkage of about 750 microstrains, followed by OPC mortar. When saturated fine LWA was used to control autogenous shrinkage, known as internal curing, of GGBFS mortar, it was found that CTE of mortar increased but net shrinkage strongly decreased, to as low as about 550 microstrains. This was attributed to great reduction of autogenous shrinkage of LWA mortar.

Cumulative numbers of $\mathrm{AE}$ hits recorded are presented in Fig. 10. Very clear differences were observed. Among concretes with w/b ratio of 0.3 , slag concrete with limestone aggregate (C-S-L20-30) had the highest number of AE hits, while the lowest number of AE hits

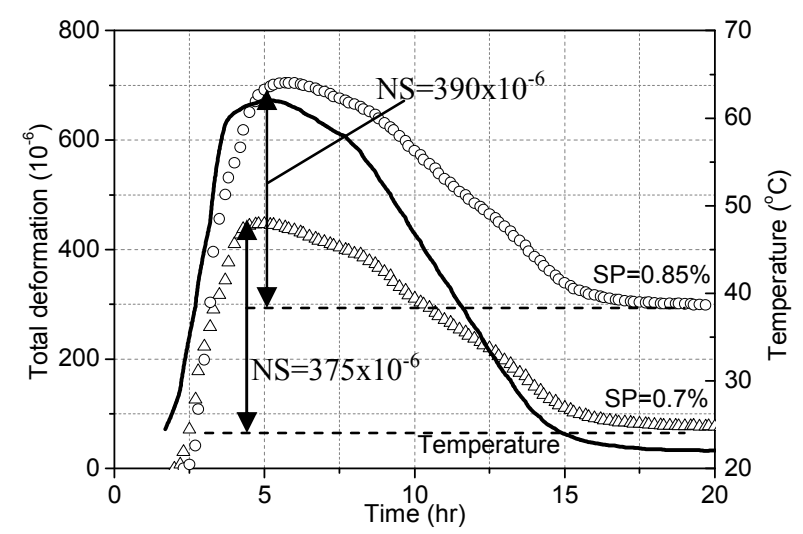

Fig. 7 Deformation of specimen (C-O-L20-30) (NS: net shrinkage; SP: superplasticizer dosage in percentage of binder weight).

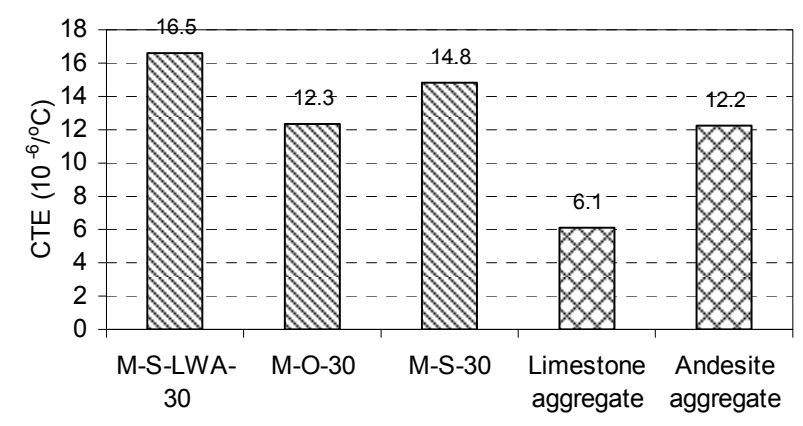

Fig. 8 Coefficient of thermal expansion (at the age of one day for mortars). 
was for the mix with LWA (C-S-L20-LWA-30). This indicates that microcracking was much more severe for concrete without LWA. As the same coarse aggregate was used for these two mixes, net shrinkage of mortars, as shown in Fig. 9, must be a crucial factor. Due to larger net shrinkage, the value of $\Delta D_{t}+S_{m}$ of Eq. (3) for slag concrete without LWA was also bigger, which in turn resulted in higher stresses $\sigma_{r}$ and $\sigma_{t}$.

Considering concretes with the same mortar (GGBFS) but different types of coarse aggregates, i.e. limestone and andesite, the number of $\mathrm{AE}$ hits recorded in limestone concrete was considerably higher than that of andesite. Here, autogenous shrinkage of mortar $S_{m}$ was the same for the two concretes but thermal deforming incompatibility $\Delta D_{t}$ of C-S-L20-30 was higher than that of C-S-A20-30 because limestone has much lower CTE (Fig. 8).

The numbers of AE hits detected for concretes with $\mathrm{w} / \mathrm{b}$ ratio of 0.5 were significantly smaller but in a similar trend with that of concretes with $\mathrm{w} / \mathrm{b}$ ratio of 0.3 . Slag concrete (C-S-L20-50) emitted more AE waves than OPC concrete (C-O-L20-50). Two of the reasons for the low number of $\mathrm{AE}$ hits in concretes with higher $\mathrm{w} / \mathrm{b}$ ratio were likely less damage from lower autogenous shrinkage $\left(S_{m}\right)$ and the lower stiffness $\left(E_{m}\right)$ of its mortar.

Direct and splitting tensile strengths are presented in Fig. 11. Whereas only direct tensile strength is used in this section, the splitting tensile strength is included in the discussion of the effect of microcracks on the difference of these two strengths in section 3.2. In Fig. 12, the ratios of tensile strengths of concretes to respective mortars and numbers of AE hits showed good correlation, which the larger the number of AE hits, the lower the tensile strength of concrete as compared with the respective mortar. This relationship most likely is the result of the extents of microcracks. Among the concretes in consideration, only concrete with LWA showed higher direct tensile strength than its mortar. This was probably due to the best harmonization in deformation of LWA mortar and coarse aggregates. The worst case was observed for concrete with normal slag mortar and limestone aggregates. In this mix, two undesirable attributes, a big gap between CTE of slag mortar and limestone, and large autogenous shrinkage of slag mortar, existed concurrently. As a result, the tensile strength of this concrete was $34 \%$ lower than that of the respective mortar. Correspondingly, the total number of $\mathrm{AE}$ hits registered for LWA concrete was the smallest (320 hits) while that of slag concrete with limestone aggregate was 779 hits. Slag concrete with andesite presented better performance where a $20 \%$ reduction in tensile strength could be seen. OPC concrete was better compared with slag concrete with the same aggregate type (limestone), probably due to the smaller net shrinkage of OPC mortar (Fig. 9). Only an 8\% reduction in tensile strength for OPC concrete compared to that of its mortar was recorded.

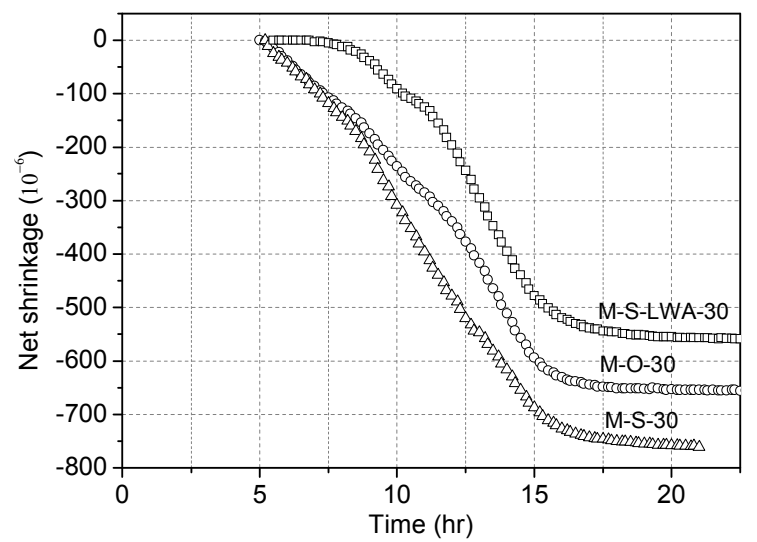

Fig. 9 Net shrinkage of mortars.

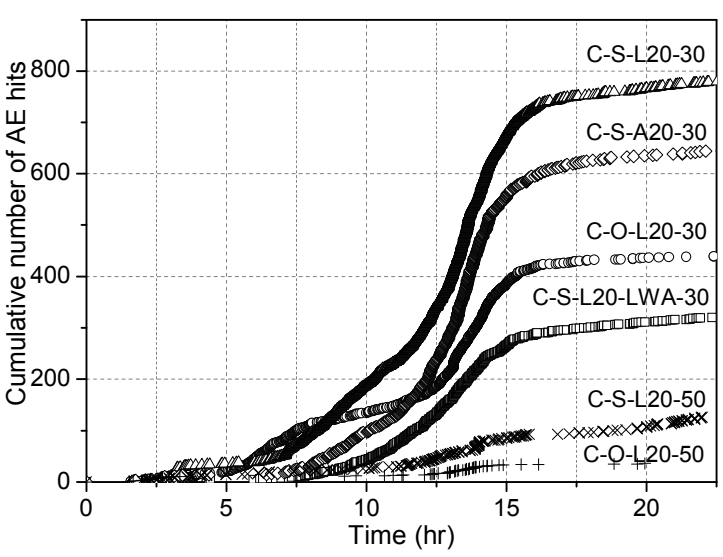

Fig. 10 Cumulative number of AE hits.

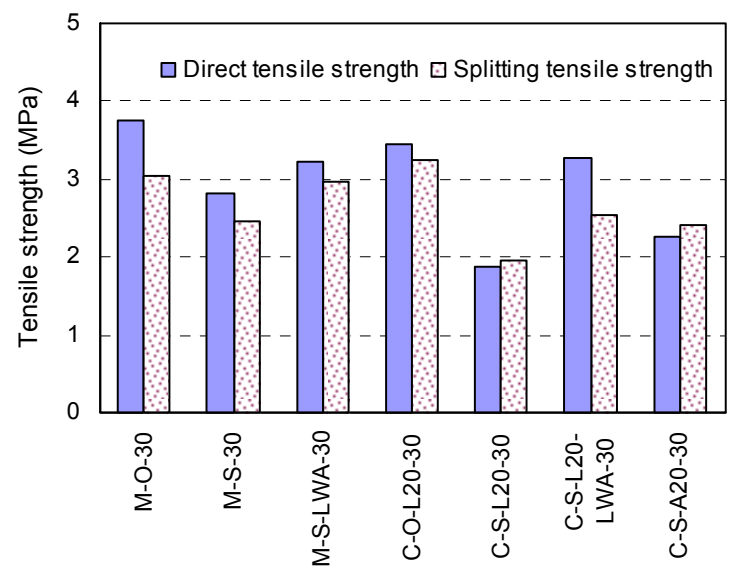

Fig. 11 Tensile strength of mortars and concretes (aggregate max. size $=19 \mathrm{~mm}$ ).

\subsection{Effect of aggregate size}

This research revealed that changing the maximum size of coarse aggregate, while keeping the same aggregate fraction, did not affect the net shrinkage of the whole composite (Fig. 13). However, the number of AE hits 


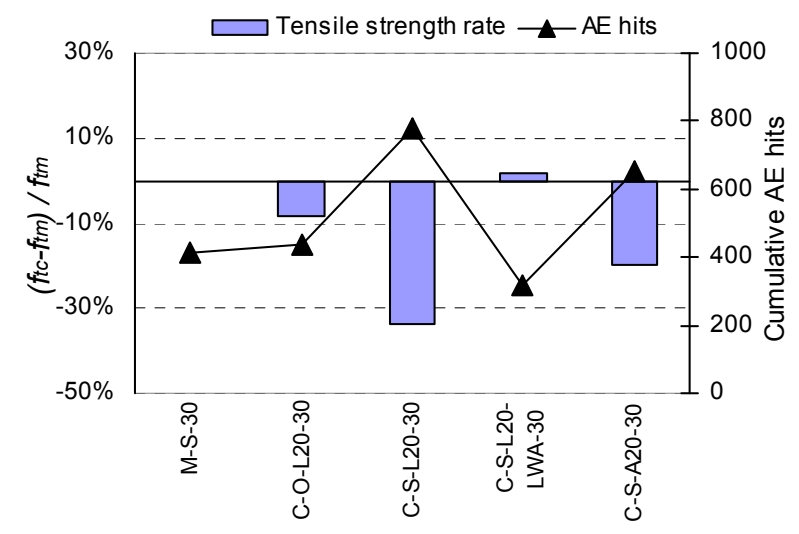

Fig. 12 Ratio of direct tensile strength of concrete / mortar and AE hits (effect of thermal and autogenous deformation).

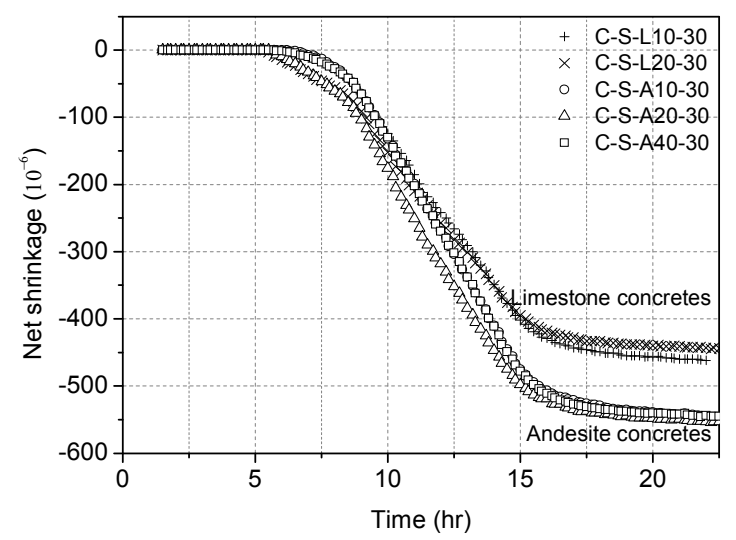

Fig. 13 Net shrinkage of concretes.

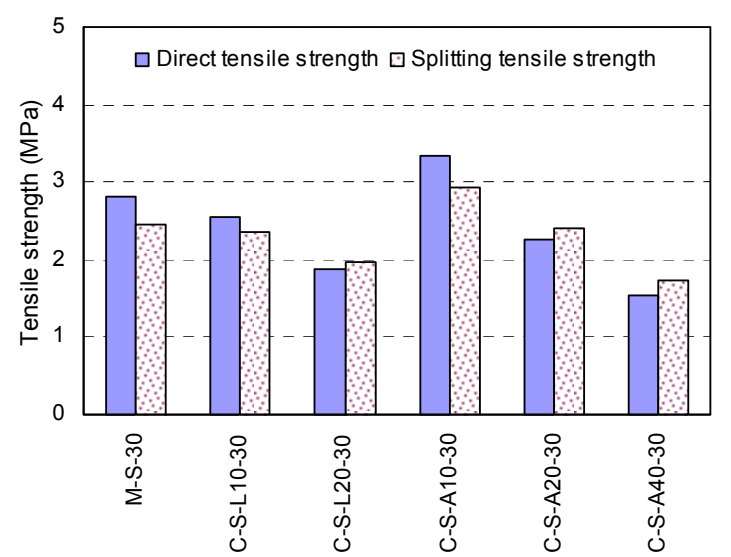

Fig. 14 Tensile strengths of mortars and concretes with different max. sizes of aggregate.

registered and tensile strengths were strongly affected (Fig. 14). Investigation carried out for concrete with maximum coarse aggregate sizes of 9.5, 19 and 37.5 $\mathrm{mm}$ showed that the larger the maximum aggregate size, the higher the number of AE hits and the lower the tensile strength. This suggests that more severe micro- cracking occurred in concretes with larger size of coarse aggregate.

Figures 15a and 15b describe the relationship between the cumulative number of AE hits and the fraction of direct tensile strengths of concretes to those of the respective mortars. Clearly the losses of tensile strengths of concretes compared with those of the respective mortars were in the same tendency with the AE hits registered for both concretes with limestone and andesite. For limestone concrete, tensile strength of concrete with maximum aggregate size of $9.5 \mathrm{~mm}$ was $10 \%$ lower than that of mortar, but that for concrete with maximum aggregate size of $19 \mathrm{~mm}$ was $34 \%$. The numbers of AE hits were 611 and 779, respectively. As discussed previously in this paper, andesite concrete with GGBFS probably suffered less internal damage than limestone concrete. Andesite aggregate with maximum size of $9.5 \mathrm{~mm}$ even made a concrete $19 \%$ stronger than mortar in tension. The lowest tensile performance was observed for concrete with andesite with maximum size of $37.5 \mathrm{~mm}$, where as much as $46 \%$ of tensile strength was lost.

Previous research (Xie et al. 1991; Caliskan et al. 2004) argued that aggregate size affects the thickness, density and bond strength of the interfacial transition zone. Additionally, based on the AE results in this research, it has been proved that microcracking in concrete with a high temperature history is also strongly affected by aggregate size. Looking back at Eqs. (1) and (2), fraction $R / r$ plays a crucial role in building up the stresses $\sigma_{r}$ and $\sigma_{t}$ in mortar. Considering a point located at a constant distance from the aggregate surface, the fraction $R / r$ definitely increases along with aggregate radius $R$. This accounts for the more severe deterioration in concretes with larger aggregate sizes.

Although it is more suitable to use direct tensile strength to study cracking, splitting tensile strength is still frequently included in specifications. The relationship between these two strengths is complicated and has not been defined well. The experimental results of this research (Figs. 11 and 14) show that concretes with GGBFS (without LWA) and maximum aggregate size of $19 \mathrm{~mm}$ or larger have direct tensile strength lower than the respective splitting tensile strength. Conversely, direct tensile strength was higher for the rest. Plotting the ratios of splitting tensile strengths over direct tensile strengths $f_{s t} / f_{d t}$ along with cumulative AE hits (Fig. 16), a relatively strong correlation was realized. Generally, the higher the number of AE hits, the lower direct tensile strength of concrete compared with the respective splitting tensile strength. This suggests that direct tensile strength was more adversely affected by the degree of microcracking than splitting tensile strength.

\subsection{Characteristics of microcracking}

It is interesting to observe that almost all $\mathrm{AE}$ activities for all specimens took place within the declining curing temperature zone. An example is given in Fig. 17a for 

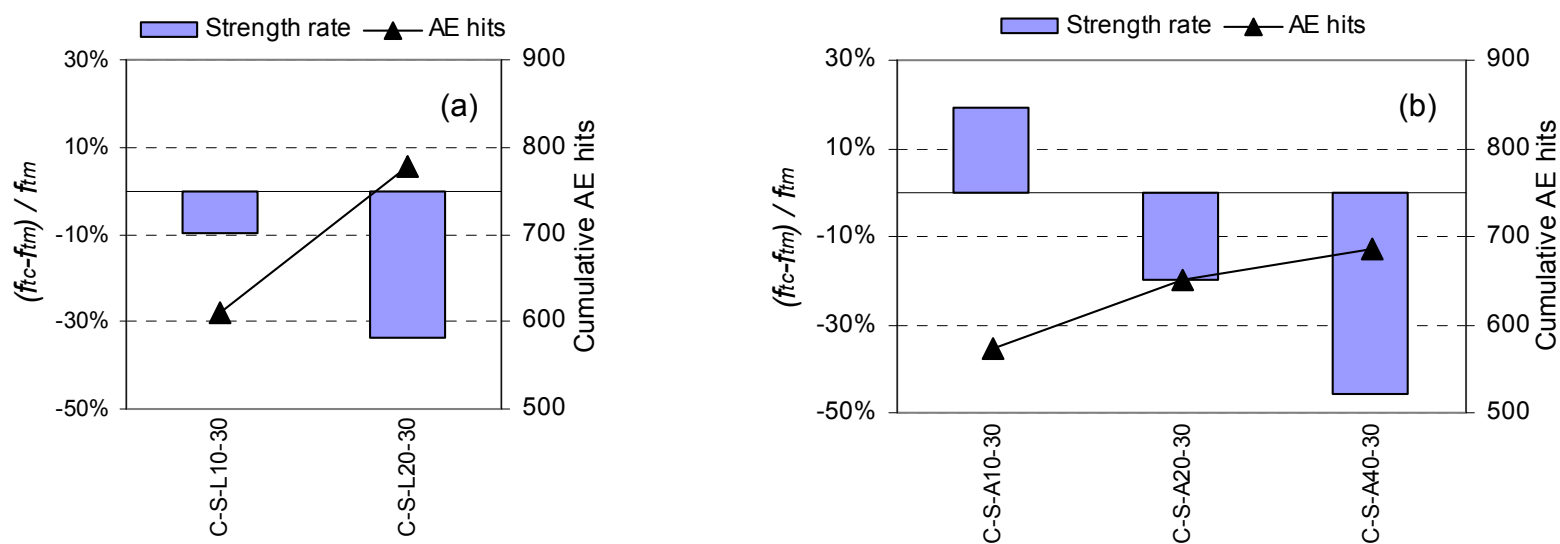

Fig. 15 Ratio of direct tensile strength of concrete / mortar and AE hits (effect of aggregate size): (a) Limestone coarse aggregate; (b) Andesite coarse aggregate.

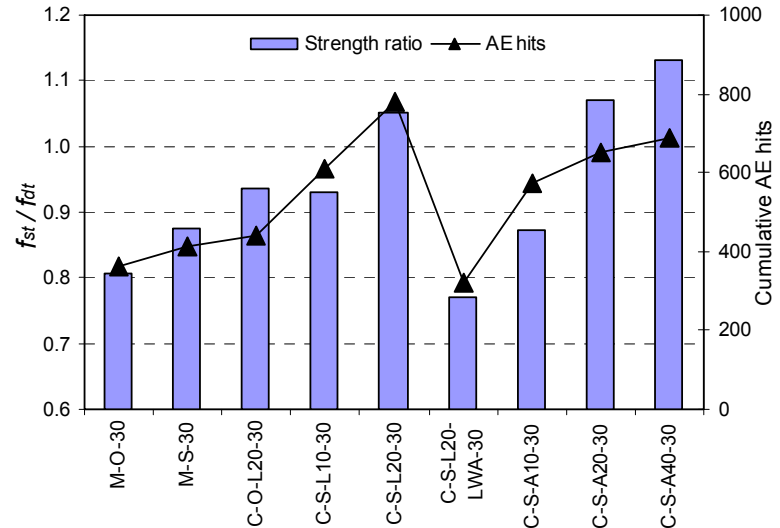

Fig. 16 Ratio of splitting / direct tensile strengths and number of $A E$ hits.

the mix of C-S-A10-30. In Fig. 17b, the same trend was observed when concretes were subjected to a second heating-cooling cycle at the age of two days. This second heating-cooling cycle was to investigate the further deterioration of concrete under the fluctuation of temperature in the real environment.

Theoretically, in Eqs. (1) to (4), as $\alpha_{m}>\alpha_{a}$ and $\Delta T$ is negative when the temperature decreases, $\Delta D_{t}=\left(\alpha_{m^{-}}\right.$ $\left.\alpha_{a}\right) \Delta T$ is a negative value. Also, the autogenous shrinkage $S_{m}$ is negative (contraction). Therefore, radial stress $\sigma_{r}$ will be negative (compression) while tangential stress $\sigma_{t}$ will be positive (tension). Per the nature of mortar, compressive strength being much higher than tensile strength, it is likely that the failure, if any, will be in pure tension mode.

Using the RA value (rise time in milliseconds over peak amplitude in volts) and average frequency distribution, it is possible to classify the microcracking modes (Shiotani 2008; Ono 2008). The early findings of the characterization of fracture mode in concrete using the AE technique can be found in the studies of Ouyang et al. (1991), Landis and Shah (1995) and Yoon et al.
(2000). Ouyang and Landis (1995) performed moment tensor analysis to clarify the slip angle of microcracking. Yoon found that the frequency of the waveform decreased as the damage degree increased in a 4-point bending test on a reinforced concrete beam, i.e. shifting from flexural cracking to shear/bond cracking, along with an increase in duration and amplitude. In other words, shear events were characterized by a longer rise time and usually higher amplitude than tensile events (Soulioti et al. 2009), while average frequency tended to be higher for tensile cracking mode. A comparison of characteristics of AE obtained during direct tension test and during heat curing of the same mix concrete is presented in Fig. 18. Based on this result, almost all microcracks detected during the heat curing period fell into tensile mode. For direct tension, there were not only pure tension cracks but also shear cracks. One of the causes of the shear failure was likely the slippage of mortar on the surface of the aggregate. In the direct tension test, many coarse aggregates were not broken but the damage occurred at the interfacial transition zone, so the slippage was obvious.

\subsection{Argument for rejection of noise}

AE can be generated from sources not involving material failure including friction, impact, electric pulses and other physical sounds. Electric pulses and sound noises were rejected as discussed in section 2.3. Impact caused by vibration of the temperature controlled chamber machinery was also eliminated by using a damping buffer.

Still, friction remains a concern. As can be seen in Fig. 17a, almost all AE hits were recorded only in the temperature decline period. This was even true for hardened concrete as shown in Fig. 17b. Logically, if AE were generated from the friction between the specimen and the wave-guide or the mold, or even between the concrete components, there should be AE hits in both the temperature decline and increase periods. The fact that this was not so indicated that the effect of friction on the AE testing results was inconsiderable. 

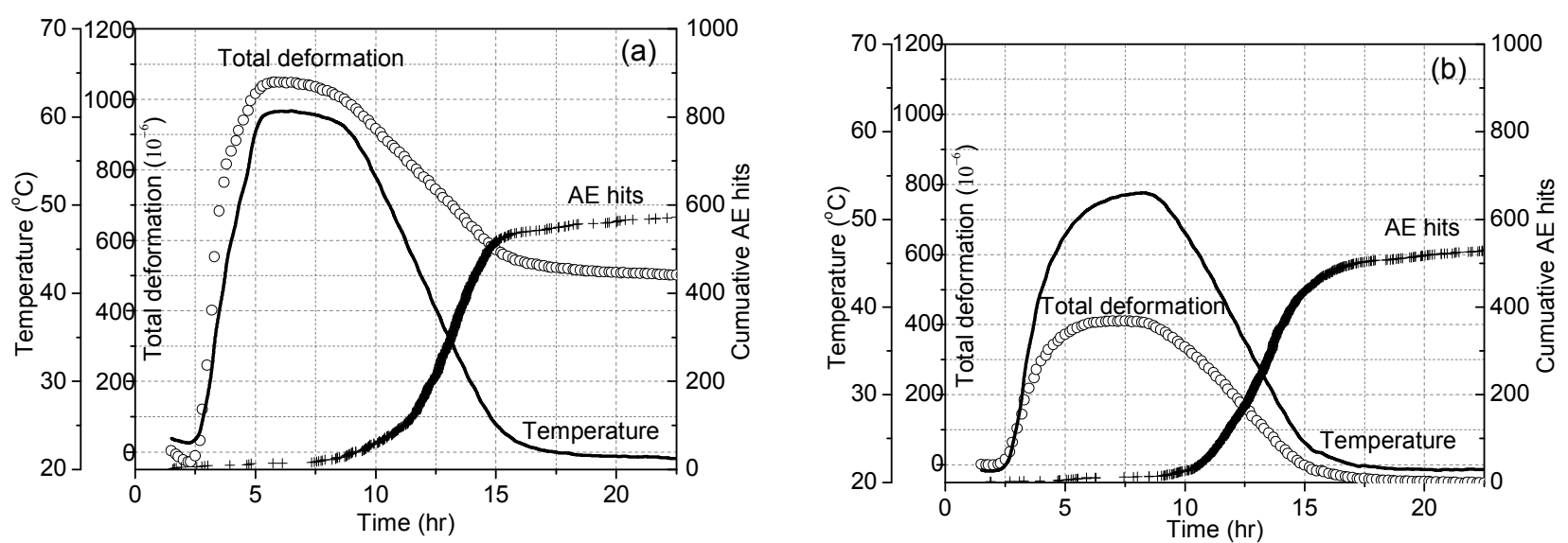

Fig. 17 Relationship between temperature, total deformation and AE hits: (a) first heating-cooling cycle; (b) second heating-cooling cycle (C-S-A10-30).

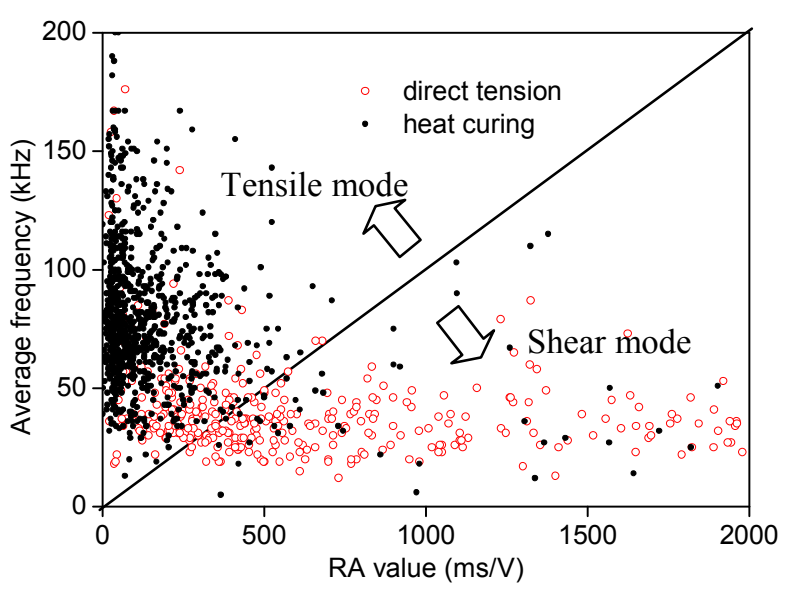

Fig. 18 Classification of crack mode.

\section{Conclusions}

Attempts were made to propose a method using the AE technique for detection of microcracking in concrete subjected to elevated temperature up to around $60^{\circ} \mathrm{C}$ at early ages. The test results showed the strong influence of CTE differences between aggregate and mortar, autogenous shrinkage of mortar and aggregate size on the development of microcracks. Greater deforming incompatibility and larger coarse aggregate size led to more serious microcracking. As a result, deterioration of concretes with $\mathrm{w} / \mathrm{b}$ ratio of 0.3 and $50 \%$ GGBFS replacement was remarkably more severe than for concrete prepared from OPC alone due to higher autogenous shrinkage and higher CTE of mortar with GGBFS. In the scope of the research, andesite coarse aggregate showed better performance than limestone for concrete with GGBFS. The effectiveness of using saturated fine LWA in reducing autogenous shrinkage and mitigating microcracking of GGBFS concretes with low w/b ratio was confirmed.
Microcracks were generated principally during the temperature decline period, and most of them were in tensile mode, based on the AE results. It was also suggested that direct tensile strength was more adversely affected by the degree of microcracking than splitting tensile strength.

\section{Acknowledgements}

This research was funded by the Ministry of Education, Culture, Sports, Science and Technology of Japan through a Grant-in-Aid for Young Scientists (B); and a Grant-in-Aid for Joint Research (A) at the Graduate School of Environment and Information Sciences at Yokohama National University. Sincere appreciation goes to Dr. Takeshi Watanabe at The University of Tokushima, Dr. Naoya Kasai at Yokohama National University for their very kind and valuable advice.

\section{References}

Ahmed, L., David, C., Abdelhafid, K. and Jean-Yves, L. T. (2000). "A new approach to determine autogenous shrinkage of mortar at an early age considering temperature history." Cement and Concrete Research, 30(6), 915-922.

Akçaoğlu, T., Tokyay, M. and Celik, T. (2002). "Effect of coarse aggregate size on interfacial cracking under uniaxial compression." Materials letters, 57(4), 828833.

Bentz, D. P., Lura, P. and Roberts, J. W. (2005). "Mixture proportioning for internal curing." Concrete International (ACI), 27(2), 35-40.

Caliskan, S. and Karihaloo, B. L. (2004). "Effect of surface roughness, type and size of model aggregates on the bond strength of aggregate/mortar interface." Interface Science, 12(4), 361-374.

Celik, O. and Nicholas, J. C. (2006). "Concrete strength testing." In: Joseph F. L. and James, H. P., Significance of Tests and Properties of Concrete and Concrete-Making Materials. West Conshohoken: ASTM International, 125-140. 
Cusson, D. (2008). "Effect of blended cements on effectiveness of internal curing of HPC." Special Publication (ACI), 256, 105-120.

Landis, E. N. and Shah, S. P. (1995). "The influence of microcracking on the mechanical behavior of cement based materials." Advanced Cement Based Materials, 2(3), 105-118

Landis, E. N. and Baillon, L. (2002). "Experiments to relate acoustic emission energy to fracture energy of concrete." Journal of Engineering Mechanics, 128(6), 698-702.

Kaufmann, J. P. (2004). "Experimental identification of ice formation in small concrete pores." Cement and Concrete Research, 34(8), 1421-1427.

Li, Z., Li, F., Zdunek, A., Landis, E. and Shah, S. P. (1998). "Application of acoustic emission technique to detection of reinforcing steel corrosion in concrete." ACI Materials Journal, 95(1), 68-76.

Lura, P., Couch, J., Jensen, O. M. and Weiss, J. (2009). "Early-age acoustic emission measurements in hydrating cement paste: Evidence for cavitation during solidification due to self-desiccation." Cement and Concrete Research, 39(10), 861-867.

Minami, K., Tazawa, E. and Teranishi, S. (1990). "Effect of microscopic thermal stress on mechanical properties of concrete subjected high temperature." Journal of Materials, Concrete Structures and Pavements (JSCE), 13(420), 173-180. (in Japanese)

Mlakar, P. F., Walker, R. E., Sullivan, B. R. and Chiarito, V. P. (1984). "Acoustic emission behavior of concrete." Special Publication (ACI), 82, 619-638.

Ohtsu, M. (1995). "Acoustic emission theory for moment tensor analysis." Research in Nondestructive Evaluation, 3(3), 169-184.

Ohtsu, M. and Watanabe, H. (2001). "Quantitative damage estimation of concrete by acoustic emission." Construction and Building Materials, 15(5-6), 217224.

Ono, K., Sawada, Y., Utsunomiya, K. and Ohtsu, M. (2008). "Classification of micro-cracks generated in concrete by acoustic emission." Progress in Acoustic Emission XIV, The Japanese Society for NDI, 347-354.

Otsuka, K. et al. (1995). "Properties of microcracks formed on surface of concrete at steam curing period", Journal of Materials, Concrete Structures and
Pavements (JSCE), 28(520), 143-155. (in Japanese).

Ouyang, C., Landis, E. and Shah, S. P. (1991). "Damage assessment in concrete using quantitative acoustic emission." Journal of Engineering Mechanics, 117(11), 2681-2698.

Ramadan, S., Gaillet, L., Tessier, C. and Idrissi, H. (2007). "Detection of stress corrosion cracking of high-strength steel used in prestressed concrete structures by acoustic emission technique." Applied Surface Science, 254(8), 2255-2261.

Reginald Hardy, H. (2003). "Acoustic Emission Microseismic Activity." Vol. 1, Principles, Techniques and Geotechnical Applications. Pennsylvania: A. A. Balkema.

Shiotani, T. (2008). "Parameter analysis." In: Grosse, C. U. and Ohtsu, M., Acoustic Emission Testing. Berlin: Springer-Verlag, 41-51.

Son, H. N. and Hosoda, A. (2008). "Mechanical properties of slag cement concrete cured at elevated temperature." In: 8th International Symposium on Utilization of High-Strength and High-Performance Concrete, Tokyo 27-29 October 2008, 523-528.

Soulioti, D., Barkoula, N. M., Paipetis, A., Matikas, T. E., Shiotani, T. and Aggelis, D. G. (2009). "Acoustic emission behavior of steel fibre reinforced concrete under bending." Construction and Building Materials, 23(12), 3532-3536.

Tazawa, E., Minami, K., Kageyama, S. and Watanbe, Y. (1987). "Influences of aggregate types on mechanical properties of concrete subjected to high temperature." Proceedings of the Japan Concrete Institute, 9(1), 1318. (in Japanese)

Xie, P., Beaudoin, J. J. and Brousseau, R. (1991). "Effect of aggregate size on transition zone properties at the Portland cement paste interface." Cement and Concrete Research, 21(6), 999-1005.

Yang, Y., Sato, R. and Kawai, K. (2005). "Autogenous shrinkage of high-strength concrete containing silica fume under drying at early ages." Cement and Concrete Research, 35(3), 449-456.

Yoon, D. J., Weiss, W. J. and Shah, S. P. (2000). "Assessing damage in corroded reinforced concrete using acoustic emission." Journal of Engineering Mechanics, 126(3), 273-283. 